\title{
Prevalence of Generalized Anxiety Disorder (GAD) Among Saudi Medical Students and Associated Risk Factors
}

\author{
Abeer Alatawi ${ }^{1}$, Ali Alghamdi ${ }^{2}$, Abdulaziz Albalwi ${ }^{3}$, Malik Altayar ${ }^{4}$, Mohammed Jalal ${ }^{4}$, \\ Ehab A.M. Frah ${ }^{5}$ \\ ${ }^{I}$ Department of Nursing, Faculty of Applied Medical Sciences, Tabuk University, Saudi Arabia. \\ ${ }^{2}$ Department of Radiological Sciences, Faculty of Applied Medical Sciences, Tabuk University, Saudi Arabia. \\ ${ }^{3}$ Department of Physical Therapy, Faculty of Applied Medical Sciences, Tabuk University, Saudi Arabia. \\ ${ }^{4}$ Department of Medical Laboratory, Faculty of Applied Medical Sciences, Tabuk University, Saudi Arabia. \\ ${ }^{5}$ Department of Statistics, Faculty of Science, Tabuk University, Saudi Arabia
}

*Corresponding Author: Abeer Alatawi, Department of Nursing, Faculty of Applied Medical Sciences, Tabuk University, Saudi Arabia.

\begin{abstract}
Background: The prevalence of Generalized Anxiety Disorder (GAD) among university students represents an important and growing mental health concern for which epidemiological data are needed.

Objectives: This study aims to estimate the prevalence of Generalized Anxiety Disorder among undergraduate students at the University of Tabuk and evaluate the related social risk factors.

Materials and Methods: We conducteda cross-sectional study from September to October 2019 among students at the University of Tabuk Faculty of Applied Medical Sciences (FAMS), which consists of three major departments (nursing, physical therapy, and medical laboratory technology) and has 550 male and female students. Participants were assessed for GAD using an electronic self-administered questionnaire consisting of two sections: demographic information (gender, age, marital status, university department, academic year, living standards, employment status, grade point average (GPA), and medical history) and the Generalized Anxiety Disorder Questionnaire (GAD-7).

Results: A total of 231 (42\%) responses were returned. More than half 146 (63.2\%) of the respondents were male and $85(36.8 \%)$ were female. The mean age of participants was $20.87 \pm 1.5$ years. About $68 \%$ of total respondents reported feeling nervous, anxious, or on edge to some degree; $10.4 \%$ said that they experience this feeling nearly every day. Female students reported higher anxiety levels, with a mean score of8.06 compared to 6.67 among male students. Smokers, low-income, and higher-GPA students were more anxious than other groups.
\end{abstract}

Conclusion: These findings highlight the need to design treatment plans to manage anxiety symptoms and lower GAD prevalence among students.

Keywords: Anxiety disorder, university students, Saudi Arabia

\section{INTRODUCTION}

Anxiety disorders, including panic disorder with or without agoraphobia, generalized anxiety disorder, social anxiety disorder, specific phobias, and separation anxiety disorder, are prevalent in the general population and constitute a major health problem (1-3). About $50 \%$ of those who suffer from anxiety disorders report that their symptoms began during childhood (3). Studies have indicated that one third of the population experience an anxiety disorder during their lifetimes (3). Individuals with anxiety disorder typically report having nervousness, intense fear, worry, or uneasiness that lasts for a long period of time and significantly affects their daily activities (4). It is more likely to occur among those with a family history of an anxiety disorder (5).

GAD is one of the most common anxiety disorders, characterized by persistent and excessive worry, anxiety symptoms, and tension (6). It is an extraordinarily serious condition if left untreated, and it may lead to other disorders such as depression (7). GAD is one of the most prevalent anxiety disorders among college students worldwide (8) and is more common among females than males (8). It can negatively affect students' academic performance, dropout 
rates, and professional development (9). This demonstrates the need to raise awareness of GAD among students.

Some common factors are associated with GAD, such as gender, marital status, poor health, low educational achievement, and the presence of stressors (10). Several scales are used to evaluate and diagnose GAD. The GAD-7 has been validated as a diagnostic and assessment tool (10). Al-Sughayr and Ferwana (11) found that the prevalence of psychiatric disorders in high school students was $48 \%$ and was higher in females $(51 \%)$ than in males $(41 \%)$. However, the study found no association between psychiatric disorders and other social variables (family size, polygamous family, or birth order) or smoking (11). A study conducted in the United Arab Emirates indicated that the prevalence rate for anxiety (56\%) was higher than that of other disorders such as depression (12). Nevertheless, little attention has been given to anxiety disorders by the medical community in Middle Eastern countries.

While health researchers have devoted significant attention to depression in recent years, relatively little focus has been placed on GAD. Therefore, our research investigates the prevalence of GAD among Saudi students in the Faculty of Applied Medical Sciences at Tabuk University and considers the associated social risk factors.

\section{Methodology}

\section{Description of Participants}

We conducted a cross-sectional study from September to October 2019 among the students at the University of Tabuk Faculty of Applied Medical Sciences (FAMS), which consists of three major departments (nursing, physical therapy, and medical laboratory technology) with 550 male and female students.

\section{Data Collection}

The data were collected with the participants' consent using an electronic self-administered questionnaire consisting of two sections: demographic information (gender, age, marital status, university department, academic year, living standards, employment status, grade point average (GPA), and medical history) and the Generalized Anxiety Disorder Questionnaire (GAD-7).

Generalized Anxiety Disorder Questionnaire (GAD-7)

The GAD-7 is a 7-item self-reported scale developed to test for the defining symptoms of
GAD. Items are rated on a 4-point Likert-type scale by how frequently they are experienced, ranging from 0 (not at all) to 3 (nearly every day). GAD-7 items assess some of the most salient diagnostic features of GAD (feeling nervous, anxious, on edge, or excessively worried). Scores range from 0 to 21 , with a greater score indicating more severe GAD symptoms. Studies have shown that the GAD-7 is a reliable screening test for assessing the severity of GAD in research and clinical settings (13). Total scores on the GAD-7 are interpreted as follows: <5 (normal), 5-9 (mild anxiety), 10-14 (moderate anxiety), and 15-21 (severe anxiety).

\section{Data Analysis}

We analysed the questionnaire results using the statistical software SPSS version 22.0 (IBM Corp, Armonk, New York). The distribution of students was determined according to demographic, social, and academic information across departments; data were expressed as the mean $( \pm$ STD). The statistical analysis was performed using SPSS to determine whether there are statistically significant differences in response patterns between student groups. We used one-way Analysis of Variance (ANOVA) at $\mathrm{p}=0.05$ to determine the relationship between GAD-7 score and sociodemographic characteristics.

\section{Ethical Approval}

Ethical approval was obtained from the Tabuk University Local Research Ethical Committee (LREC) (reference number UT-94-16-2019). Participants were informed that they had the right to refuse participation in the study or withdraw at any time. To maintains students' privacy, data were kept confidential and used for study purposes only. All students understood and signed an electronic consent before participation in this study.

\section{RESULTS}

\section{Description of Participants}

The online questionnaire was distributed to 550 students in the Faculty of Applied Medical Sciences at the University of Tabuk in September and October 2019. A total of 231 responses $(42 \%)$ were returned. More than half of respondents $(\mathrm{n}=146,63.2 \%)$ were male and $85(36.8 \%)$ were female.

Demographic and academic information provided the distribution of participants 
Prevalence of Generalized Anxiety Disorder (GAD) Among Saudi Medical Students and Associated Risk Factors

according to their gender, age, department, academic year, marital status, GPA, English proficiency, income, employment status (Table 1), and frequency of physical activity (Fig. 1). The mean age of participants was $20.87 \pm 1.5$ years. The largest group was students from the nursing department $(n=106,45.9 \%)$, followed by physical therapy $(\mathrm{n}=63,27.3 \%)$ and medical laboratory technology $(\mathrm{n}=62,26.8 \%)$. Families were classified as low-income $(\mathrm{n}=22,9.5 \%)$, middle-income $(\mathrm{n}=157,68 \%)$ or high income $(n=29,12.6 \%)$. Only $12.6 \%$ of students were employed in a part-time job.

Table1. Distribution of students according to demographic, social, and academic information.

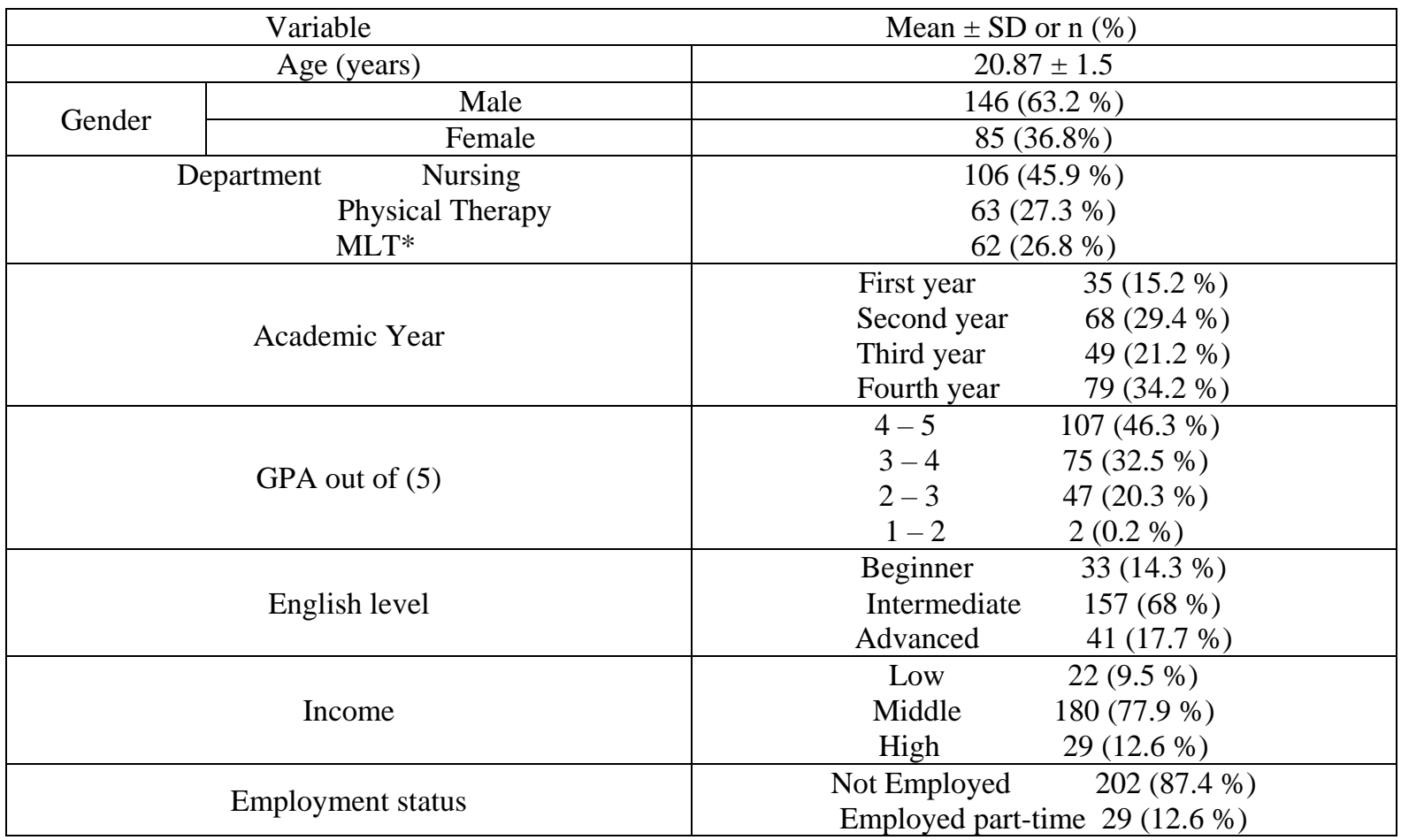

*MLT: Medical Laboratory Technology

The distribution of students according to their number of weekly physical activities is shown in Figure 1. The largest group of students $(n=94,41 \%)$ exercised once a week while only $10(4 \%)$ exercised every day.

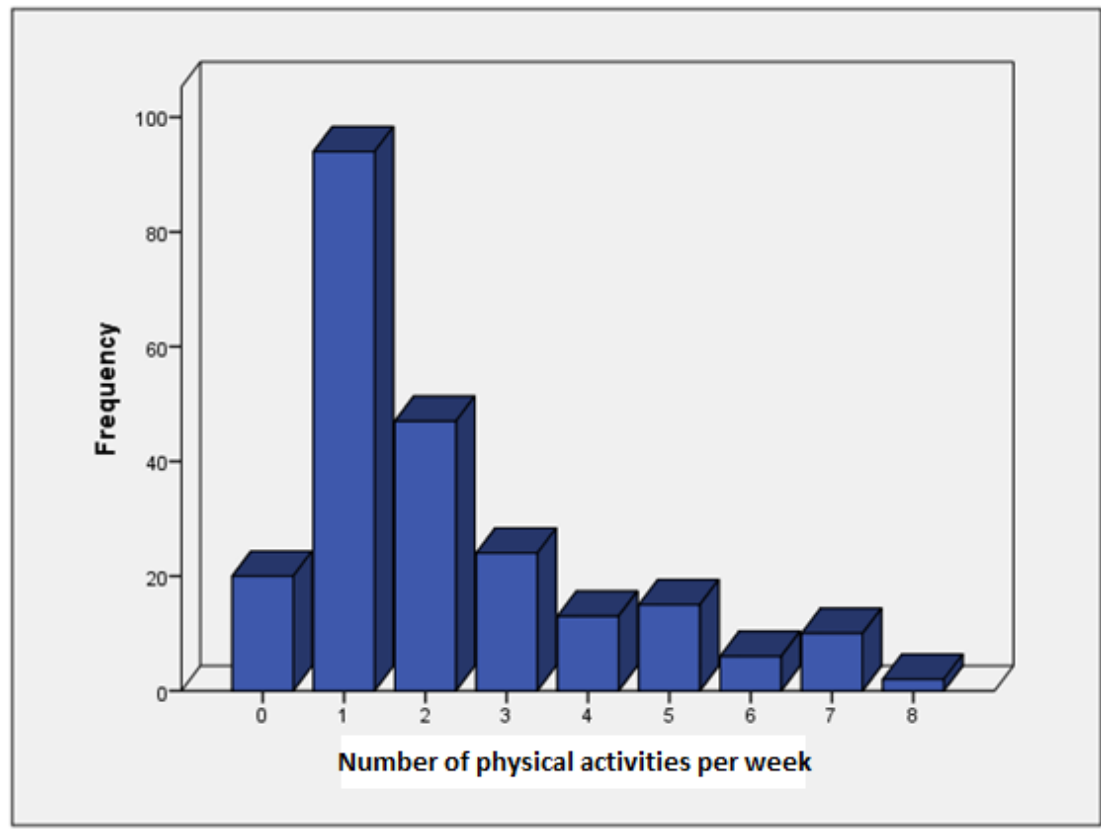

Figure1. Distribution of students according to their number of weekly physical activities 
Prevalence of Generalized Anxiety Disorder (GAD) Among Saudi Medical Students and Associated Risk Factors

Table2. shows the distribution of students in each GAD-7 question. About $68 \%$ of total respondents reported feeling nervous, anxious, or on edge to some degree, with $10.4 \%$ saying that they experience this feeling nearly every day. "Worrying too much about different things" was the symptom that students most commonly reported experiencing every day, at $19.5 \%$, while "being so restless that it's hard to sit still" was the least common at $4.3 \%$.

\begin{tabular}{|l|c|c|c|c|}
\hline & Not at all & Several days & $\begin{array}{c}\text { More than half } \\
\text { of days }\end{array}$ & Nearly every day \\
\hline $\begin{array}{l}\text { Feeling nervous, anxious, or } \\
\text { on edge }\end{array}$ & $74(32 \%)$ & $97(42 \%)$ & $36(15.6 \%)$ & $24(10.4 \%)$ \\
\hline $\begin{array}{l}\text { Not being able to stop or } \\
\text { control worrying }\end{array}$ & $89(38.5 \%)$ & $94(40.7 \%)$ & $31(13.4 \%)$ & $17(7.4 \%)$ \\
\hline $\begin{array}{l}\text { Worrying too much about } \\
\text { different things }\end{array}$ & $54(23.4 \%)$ & $80(34.6 \%)$ & $52(22.5 \%)$ & $45(19.5 \%)$ \\
\hline Trouble relaxing & $87(37.7 \%)$ & $85(36.8 \%)$ & $36(15.6 \%)$ & $23(10 \%)$ \\
\hline $\begin{array}{l}\text { Being so restless that it's } \\
\text { hard to sit still }\end{array}$ & $111(48.1 \%)$ & $79(34.2 \%)$ & $31(13.4 \%)$ & $10(4.3 \%)$ \\
\hline $\begin{array}{l}\text { Becoming easily annoyed or } \\
\text { irritable }\end{array}$ & $81(35.1)$ & $85(36.8 \%)$ & $36(15.6 \%)$ & $29(12.6 \%)$ \\
\hline $\begin{array}{l}\text { Feeling afraid as if } \\
\text { something awful might } \\
\text { happen }\end{array}$ & $86(37.2 \%)$ & $73(31.6 \%)$ & $38(16.5 \%)$ & $34(14.7 \%)$ \\
\hline $\begin{array}{l}\text { If you checked off any } \\
\text { problems, how difficult have } \\
\text { these made it for you to do } \\
\text { your work, take care of } \\
\text { things at home, or get along } \\
\text { with other people? }\end{array}$ & $73(31.6 \%)$ & $132(57.1 \%)$ & $26(11.3 \%)$ & \\
\hline
\end{tabular}

\section{Distribution of GAD-7 scores}

Overall, the mean GAD-7 score among participants was $7.18 \pm 4.8$. Distribution of scores falling within GAD-7 severity cut-offs was as follows: no anxiety (32.5\%), mild anxiety (36.4\%), moderate anxiety (23.8\%), and severe anxiety $(7.4 \%)$. Based on the results, the prevalence of GAD was $67.5 \%(n=156)$ ranging from mild to severe anxiety (Fig. 2).

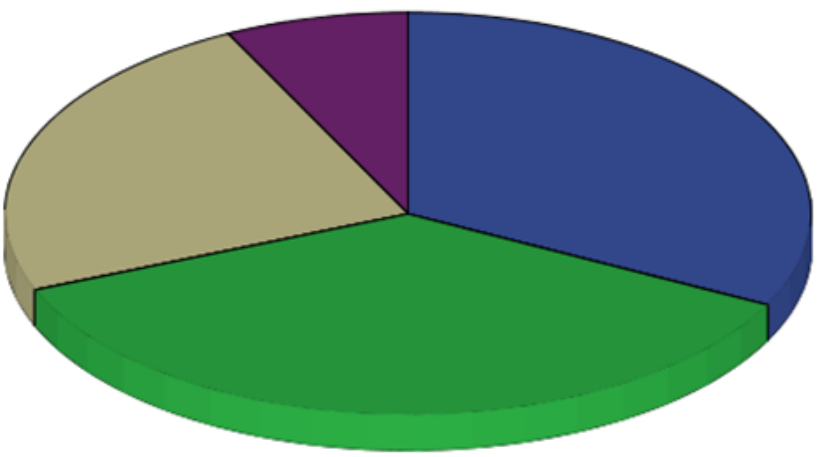

Figure2. Distribution of students according to level of anxiety.

When participants were asked, "If you checked off any problems, how difficult have these made it for you to do your work, take care of things at home, or get along with other people?", 73 students $(31.6 \%)$ reported that it is not difficult at all, $132(57.1 \%)$ said it is somewhat difficult, and $26(11.3 \%)$ said that it is very difficult (Fig. $3)$. 
Prevalence of Generalized Anxiety Disorder (GAD) Among Saudi Medical Students and Associated Risk Factors

How difficult has the anxiety made the work, take care of things at home, or get along with other people?

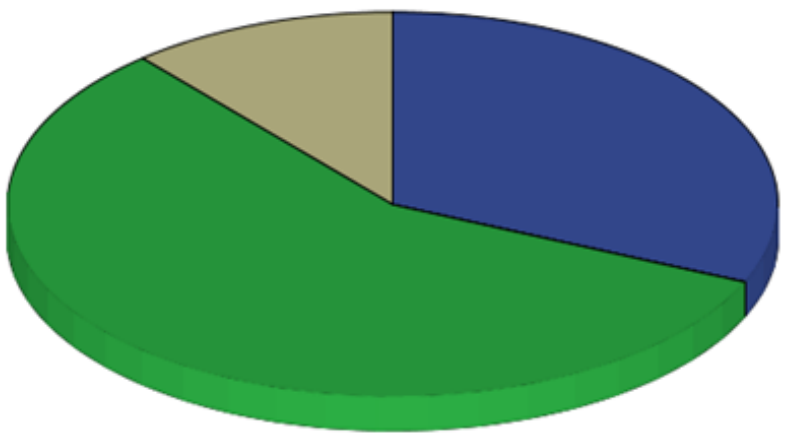

Figure3. Distribution of students according to reported difficulty in working, taking care of things, or getting along with other people due to anxiety.

\section{Factors Associated with GAD}

A t-test was used to investigate the effect of gender on total GAD-7 score. Generally, female students were more anxious than their male counterparts. The mean score for female students was 8.06 , compared to 6.67 in male students, with no significant difference $\mathrm{p}>0.05$.
Anxiety appears to increase with GPA students with the highest GPAs were the most anxious group. However, an ANOVA test showed no significant correlation ( $p>0.05$ ) between GAD-7 score and GPA. Table 3 shows the mean score and severity of anxiety associated with each variable.

Table3. The mean score and severity of anxiety associated with each variable.

\begin{tabular}{|c|c|c|c|c|}
\hline Variable & Mean score & $\mathrm{STD} \pm$ & Severity & P-value \\
\hline $\begin{array}{c}\text { Marital status } \\
\text { Single }\end{array}$ & 7.1390 & 4.7 & Mild & \\
\hline Married & 8.3750 & 6.8 & Mild & .475 \\
\hline Department & 7.0943 & 4.5 & Mild & \multirow[t]{3}{*}{.251} \\
\hline Nursing & 6.5556 & 4.8 & Mild & \\
\hline $\begin{array}{c}\text { Physical therapy } \\
\text { MLT }\end{array}$ & 7.9677 & 5.1 & Mild & \\
\hline $\begin{array}{l}\text { Academic year } \\
\text { First year }\end{array}$ & 6.7714 & 4.5 & Mild & \multirow[b]{3}{*}{.276} \\
\hline Second year & 7.8382 & 4.4 & Mild & \\
\hline $\begin{array}{l}\text { Third year } \\
\text { Fourth year }\end{array}$ & $\begin{array}{l}7.7143 \\
6.4684\end{array}$ & $\begin{array}{l}4.5 \\
5.2\end{array}$ & $\begin{array}{l}\text { Mild } \\
\text { Mild }\end{array}$ & \\
\hline $\begin{array}{l}\text { GPA } \\
4-5\end{array}$ & 7.8972 & 5.1 & Mild & \multirow[t]{3}{*}{.182} \\
\hline $3-4$ & 6.6800 & 4.6 & Mild & \\
\hline $\begin{array}{l}2-3 \\
1-2\end{array}$ & $\begin{array}{l}6.4681 \\
4.5000\end{array}$ & $\begin{array}{c}4.1 \\
.70711\end{array}$ & $\begin{array}{c}\text { Mild } \\
\text { Normal }\end{array}$ & \\
\hline $\begin{array}{c}\text { English level } \\
\text { Beginner }\end{array}$ & 6.2727 & 3.94709 & Mild & \multirow[t]{3}{*}{.051} \\
\hline Intermediate & 6.9618 & 4.89097 & Mild & \\
\hline Advanced & 8.7561 & 4.81550 & Mild & \\
\hline $\begin{array}{c}\text { English difficulty } \\
\text { Yes }\end{array}$ & 7.7638 & 4.87699 & Mild & \multirow[t]{2}{*}{.041} \\
\hline No & 6.4712 & 4.62361 & Mild & \\
\hline $\begin{array}{c}\text { Family income } \\
\text { Low }\end{array}$ & 8.3182 & 4.89301 & Mild & \multirow{3}{*}{.409} \\
\hline Middle & 7.1500 & 4.72184 & Mild & \\
\hline High & 6.5172 & 5.20728 & Mild & \\
\hline
\end{tabular}


Prevalence of Generalized Anxiety Disorder (GAD) Among Saudi Medical Students and Associated Risk Factors

\begin{tabular}{|c|c|c|c|c|}
\hline Employed? & 7.1535 & 4.80062 & Mild & \multirow[t]{2}{*}{.813} \\
\hline $\begin{array}{c}\text { No } \\
\text { Yes (part-time) }\end{array}$ & 7.3793 & 4.85808 & Mild & \\
\hline Smoker & 8.4000 & 4.99641 & Mild & \multirow[t]{2}{*}{.077} \\
\hline Non-smoker & 6.9267 & 4.72896 & Mild & \\
\hline $\begin{array}{c}\text { Chronic disease } \\
\text { Yes } \\
\end{array}$ & 9.0000 & 4.53557 & Mild & \multirow[t]{2}{*}{.029} \\
\hline No & 6.9208 & 4.78843 & Mild & \\
\hline $\begin{array}{c}\text { Physical activity } \\
\text { Walk }\end{array}$ & 7.2256 & 4.63128 & Mild & \multirow[t]{5}{*}{.016} \\
\hline \multirow{4}{*}{$\begin{array}{c}\text { Run } \\
\text { Lift weights } \\
\text { Swim } \\
\text { Play a team sport }\end{array}$} & 8.4783 & 3.71569 & Mild & \\
\hline & 5.3500 & 4.76031 & Mild & \\
\hline & 10.9000 & 5.82046 & Moderate & \\
\hline & 7.1034 & 5.65272 & Mild & \\
\hline
\end{tabular}

Surprisingly, students with the highest English proficiency showed the highest levels of anxiety, trending to significance at $\mathrm{p}=0.051$. For example, students with advanced English proficiency reported a mean score of $8.76 \pm 4.8$, followed by those with intermediate proficiency $(6.96 \pm 4.8)$ and beginners $(6.27 \pm 3.9)$. Interestingly, level of anxiety increased significantly in students with advanced English skills, compared to those with intermediate skills and beginners ( $\mathrm{p}=.033$ and $\mathrm{p}=.027$, respectively).

However, more than half of students 127 (55\%) said that they had academic difficulties due to studying subjects in English (a second language), while 104 (45\%) stated that they had no difficulties. Those who complained of English difficulties were more anxious, with a mean score of 7.7 compared to 6.5 among students having no English difficulties ( $\mathrm{p}=.041)$.

In addition, we noticed that smokers (17\%) had higher mean anxiety scores (8.4) than nonsmokers (83\%), who were less anxious (mean score 6.9). This indicates higher anxiety levels among smokers $(\mathrm{p}=.077)$. Of total respondents, $8.7 \%$ had chronic diseases; these students were more anxious (mean score 9.0) than the remaining $91.3 \%$ of students, who were healthy (mean score 6.9, $\mathrm{p}=.029$ ).

Regarding physical activities, students who lifted weights were the least anxious group (mean score 5.4), followed by those who played a team sport such as football (mean 7.1), walkers (mean 7.2), and runners (mean 8.2); the most anxious group were those practicing swimming (mean $=10.9, \mathrm{p}=0.016$ ).

\section{DISCUSSION}

GAD is one of the most common anxiety disorders and can lead to other major problems, such as severe depression. Early detection is crucial to overcoming this problem and improving quality of life. The GAD-7 scale, developed by Spritzer and colleagues in 2006, is highly regarded as a valid tool for screening GAD and measuring its severity $(13,14)$ in various disciplines. Because the GAD-7 scale has been utilised in several previous publications $(13,15-18)$, we selected it as our tool to evaluate GAD and determine its prevalence in a sample of FAMS students at the University of Tabuk. To our knowledge, this is the first paper from Saudi Arabia, and Tabuk in particular, to assess the prevalence of GAD among students using this version of the questionnaire.

Previous research has shown that an increased prevalence of anxiety among medical and health sciences students is to be expected (19-22). There are many factors that can explain this, such as sociodemographic factors. This study found a high prevalence of mild-to-severe GAD among these students $(\mathrm{n}=156,67.5 \%)$; this is similar to the anxiety prevalence $(54.5 \%)$ that another study reported among medical students (23). The mean total score on the GAD-7 was $7.18 \pm 4.8$ (mild anxiety), which was also consistent with previous studies $(23,24)$. Our results indicate the following distribution of scores according to GAD-7 severity cut-offs: no anxiety (32.5\%), mild anxiety (36.4\%), moderate anxiety (23.8\%), and severe anxiety $(7.4 \%)$.

In our sample, female students were more anxious than their male counterparts. The mean score for female students was 8.06 compared to 6.67 in male students, with no significant difference ( $p>0.05$ ). These findings were similar to those reported by previous studies performed in Egypt (25), Turkey, and Hong Kong that found high levels of anxiety and stress among women $(24,26,27)$. In contrast, other researchers have found no significant 
association between psychological disorders and gender (28).

In our study, there was no significant association between academic year and level of anxiety. This contrasts with a previous study, which reported that upperclassmen in a sample of college students scored the highest on anxiety and depression (29). Another study on university students found that first-year students were the most anxious and anxiety then decreased until the sixth year (24).

Notably, we found that anxiety increases with GPA. Students with the highest GPAs were the most anxious group, although an ANOVA test showed no significant association ( $p>0.05$ ) between GAD score and GPA. One possible explanation for this finding is that these students were excessively concerned about earning high grades, which heightened their anxiety levels. This is consistent with a previous study that reported a positive correlation between GPA and anxiety (23). In contrast, another study examined the relationship between academic achievement and anxiety using a different scale and found no significant association (30).

In addition, students with higher levels of English proficiency reported more anxiety (mean score 8.7) than beginners (6.2) or students with intermediate skills (6.9). This is perhaps because students with greater English proficiency had higher GPAs and were consequently more anxious about maintaining them.

Employed and non-employed students had almost the same mean GAD-7 scores - 7.2 and 7.4, respectively. Smokers reported a higher level of anxiety (mean score 8.4) than nonsmokers $(6.9, \mathrm{p}=0.077)$. This prompts the question of what comes first: Are anxious students more likely to smoke to cope with their anxiety or does smoking increase anxiety levels? Interestingly, a previous study (31) found that smokers with anxiety disorders had more severe physical and mental symptoms than non-smokers; however, smokers with GAD had significantly lower levels of social anxiety than non-smokers.

Students with known chronic diseases such as diabetes, hypertension, and hypothyroidism reported higher anxiety levels (mean score 9) than healthy students (6.9). This is unsurprising, as these students may be overwhelmed by their disease follow-ups at clinics.
There was no significant association between the number of physical activities per week and anxiety. However, the type of activity was significantly associated with anxiety levels $(\mathrm{p}=0.016)$. Specifically, students who lifted weights were the least anxious group (mean score 5.4) followed by students who participated in a team sport such as football or basketball (7.1). Students who participated in swimming were the most anxious group, with a mean score of 10.9 - the highest score of all groups. Further study is needed to analyse the relationship between anxiety and the type of sport in which students engage.

In our study, it was obvious that anxiety levels increase as family income decreases. Lowincome students were more anxious (mean score 8.3) than students with middle (7.1) or high income (6.5) ( $p>0.05)$. Other studies have shown that low income is correlated with psychological disorders such as depression $(32,33)$.In addition, previous research has reported that academic level, place of residence, and perceived economic status are associated with anxiety symptoms (34).

We found alarming anxiety levels among students, regardless of the variables tested, which may assist the university or other authorities in considering measures to address this concern to prevent the progression of GAD to more severe levels. This study paves the way for conducting larger-scale investigations at other colleges or on a national scale so that comprehensive solutions can be established and implemented. Larger sample sizes and cohort studies are needed to assess this situation.

\section{CONCLUSION}

This study has demonstrated that generalised anxiety disorder is highly prevalent among students in the Faculty of Applied Medical Sciences at the University of Tabuk. It is important to detect anxiety among university students at its early stages to prevent its progression and increase quality of life. Female students, smokers, and those with a high GPA or low income reported high levels of anxiety. Our results reveal the need for prevention and treatment plans to manage anxiety symptoms and to lower the rate of affected students.

\section{ACKNOWLEDGMENT}

We would like to thank all students for their cooperation and participation in this study. 


\section{REFERENCES}

[1] Moreno-Peral P, Conejo-Cerón S, Motrico E, Rodríguez-Morejón A, Fernández A, GarcíaCampayo J, et al. Risk factors for the onset of panic and generalised anxiety disorders in the general adult population: a systematic review of cohort studies. J Affect Disord. 2014;168:337348.

[2] Kessler RC, Chiu WT, Demler O, Walters EE. Prevalence, severity, and comorbidity of 12month DSM-IV disorders in the National Comorbidity Survey Replication. Arch Gen Psychiatry. 2005;62(6):617-627.

[3] Bandelow B, Michaelis S. Epidemiology of anxiety disorders in the 21 st century. Dialogues Clin Neurosci. 2015;17(3):327.

[4] Newman MG, Llera SJ, Erickson TM, Przeworski A, Castonguay LG. Worry and generalized anxiety disorder: a review and theoretical synthesis of evidence on nature, etiology, mechanisms, and treatment. Annu Rev Clin Psychol. 2013;9:275-297.

[5] McLaughlin KA, Behar E, Borkovec TD. Family history of psychological problems in generalized anxiety disorder. J Clin Psychol. 2008;64(7):905-918.

[6] Leonard K, Abramovitch A. Cognitive functions in young adults with generalized anxiety disorder. Eur Psychiatry.2019;56(1):1-7.

[7] Arikian SR, Gorman JM. A review of the diagnosis, pharmacologic treatment, and economic aspects of anxiety disorders. Prim Care Companion J Clin Psychiatry. 2001; 3(3): 110.

[8] Auerbach RP, Alonso J, Axinn WG, Cuijpers P, Ebert DD, Green JG, et al. Mental disorders among college students in the World Health Organization world mental health surveys. Psychol Med. 2016;46(14):2955-2970.

[9] Tian-Ci Quek T, Tam W-S, X Tran B, Zhang M, Zhang Z, Su-Hui Ho C, et al. The Global Prevalence of Anxiety Among Medical Students: A Meta-Analysis. Int J Environ Res Public Health. 2019;16(15):2735.

[10] Munir S, Gondal AZ, Takov V. Generalized Anxiety Disorder (GAD). In: StatPearls [Internet]. StatPearls Publishing; 2019.

[11] Al-Sughayr AM, Ferwana MS. Prevalence of mental disorders among high school students in National Guard Housing, Riyadh, Saudi Arabia. J Fam Community Med. 2012;19(1):47.

[12] Mahmoud I, Saravanan C. Prevalence of Mental Disorders and the Use of Mental Health Services among the Adult Population in United Arab Emirates. Asian J Epidemiol. 2020;13(1):12-19.

[13] Spitzer RL, Kroenke K, Williams JB, Löwe B. A brief measure for assessing generalized anxiety disorder: the GAD-7. Arch Intern Med. 2006;166(10):1092-1097.

[14] Rutter LA, Brown TA. Psychometric properties of the generalized anxiety disorder scale-7 (GAD-7) in outpatients with anxiety and mood disorders. J Psychopathol Behav Assess. 2017;39(1):140-146.

[15] Jordan P, Shedden-Mora MC, Löwe B. Psychometric analysis of the Generalized Anxiety Disorder scale (GAD-7) in primary care using modern item response theory. PloS One. 2017;12(8):e0182162.

[16] Löwe B, Decker O, Müller S, Brähler E, Schellberg D, Herzog W, et al. Validation and standardization of the Generalized Anxiety Disorder Screener (GAD-7) in the general population. Med Care. 2008;266-274.

[17] Terrill AL, Hartoonian N, Beier M, Salem R, Alschuler $\mathrm{K}$. The 7-item generalized anxiety disorder scale as a tool for measuring generalized anxiety in multiple sclerosis. Int $\mathbf{J}$ MS Care. 2015;17(2):49-56.

[18] Seo J-G, Park S-P. Validation of the Generalized Anxiety Disorder-7 (GAD-7) and GAD-2 in patients with migraine. J Headache Pain. 2015;16(1):97.

[19] Mayer FB, Santos IS, Silveira PS, Lopes MHI, de Souza ARND, Campos EP, et al. Factors associated to depression and anxiety in medical students: a multicenter study. BMC Med Educ. 2016;16(1):282.

[20] Yusoff MSB, Abdul Rahim AF, Baba AA, Ismail SB, Mat Pa MN, Esa AR. The impact of medical education on psychological health of students: a cohort study. Psychol Health Med. 2013;18(4):420-430.

[21] Hope V, Henderson M. Medical student depression, anxiety and distress outside North America: a systematic review. Med Educ. 2014;48(10):963-979.

[22] Chernomas WM, Shapiro C. Stress, depression, and anxiety among undergraduate nursing students. Int $\mathrm{J}$ Nurs Educ Scholarsh. 2013;10(1):255-266.

[23] Yusoff MSB, Rahim AFA, Baba AA, Ismail $\mathrm{SB}$, Pa MNM. Prevalence and associated factors of stress, anxiety and depression among prospective medical students. Asian J Psychiatry. 2013;6(2):128-133.

[24] Bayram N, Bilgel N. The prevalence and sociodemographic correlations of depression, anxiety and stress among a group of university students. Soc Psychiatry Psychiatr Epidemiol. 2008;43(8):667-672.

[25] Salem GM, Allah MBA, Said RM. Prevalence and predictors of depression, anxiety and stress among Zagazig University students. Med J Cairo Univ. 2016;84(2):325-334. 
Prevalence of Generalized Anxiety Disorder (GAD) Among Saudi Medical Students and Associated Risk Factors

[26] Vesga-López O, Schneier F, Wang S, Heimberg R, Liu S-M, Hasin DS, et al. Gender differences in generalized anxiety disorder: results from the National Epidemiologic Survey on Alcohol and Related Conditions (NESARC). J Clin Psychiatry. 2008;69(10):1606.

[27] Wong JG, Cheung EP, Chan KK, Ma KK, Wa Tang S. Web-based survey of depression, anxiety and stress in first-year tertiary education students in Hong Kong. Aust N Z J Psychiatry. 2006;40(9):777-782.

[28] Smith CK, Peterson DF, Degenhardt BF, Johnson JC. Depression, anxiety, and perceived hassles among entering medical students. Psychol Health Med. 2007;12(1):31-39.

[29] Beiter R, Nash R, McCrady M, Rhoades D, Linscomb M, Clarahan M, et al. The prevalence and correlates of depression, anxiety, and stress in a sample of college students. J Affect Disord. 2015;173:90-96.

[30] Teh CK, Ngo CW, binti Zulkifli RA, Vellasamy R, Suresh K. Depression, anxiety and stress among undergraduate students: A cross sectional study. Open J Epidemiol. 2015;5(04):260.

[31] Morissette SB, Brown TA, Kamholz BW, Gulliver SB. Differences between smokers and nonsmokers with anxiety disorders. J Anxiety Disord. 2006;20(5):597-613.

[32] Shamsuddin K, Fadzil F, Ismail WSW, Shah SA, Omar K, Muhammad NA, et al. Correlates of depression, anxiety and stress among Malaysian university students. Asian J Psychiatry. 2013;6(4):318-323.

[33] Wolff BC, Santiago CD, Wadsworth ME. Poverty and involuntary engagement stress responses: Examining the link to anxiety and aggression within low-income families. Anxiety Stress Coping. 2009;22(3):309-325.

[34] Al Bahhawi T, Albasheer OB, Makeen AM, Arishi AM, Hakami OM, Maashi SM, et al. Depression, anxiety, and stress and their association with khat use: a cross-sectional study among Jazan University students, Saudi Arabia. Neuropsychiatr Dis Treat. 2018; $14: 2755$.

Citation: Abeer Alatawi et.al, "Prevalence of Generalized Anxiety Disorder (GAD) Among Saudi Medical Students and Associated Risk Factors", International Journal of Research Studies in Medical and Health Sciences. 2020; 5(9): 01-09.

Copyright: (c) 2020 Abeer Alatawi et.al, This is an open-access article distributed under the terms of the Creative Commons Attribution License, which permits unrestricted use, distribution, and reproduction in any medium, provided the original author and source are credited. 